\title{
Retraction Note: Urban air pollution resolution and basketball training optimization based on time convolution network
}

\section{Changsong $\operatorname{Han}^{1}$}

Published online: 3 November 2021

C) Saudi Society for Geosciences 2021

Retraction Note: Arabian Journal of Geosciences (2021) 14: 1820 https://doi.org/10.1007/s12517-021-08179-9

The Editor-in-Chief and the Publisher have retracted this article because the content of this article is nonsensical. The peer review process was not carried out in accordance with the Publisher's peer review policy. The author has not responded to correspondence regarding this retraction.

The original article can be found online at https://doi.org/10.1007/ s12517-021-08179-9.

Changsong Han

xgxytyxy@163.com

1 Department of Physical Education, Hubei Engineering

University, Xiaogan 432100, Hubei, China 